\title{
Covid-19: GPs angry they were not told about changes to shielding advice
}

\author{
Gareth lacobucci
}

The BMJ

The government's sudden decision to relax its advice for patients who are most at risk from covid-19 to "shield" at home has left GP practices unprepared and vulnerable patients concerned, doctors have warned.

On Saturday 30 May, the government unexpectedly announced that 2.2 million people who had previously been told to stay at home because they were at especially high risk from covid-19 would be able to go outside with members of their household from 1 June, provided they maintained social distancing. The updated advice ${ }^{1}$ also stipulated that people who live alone can meet outside with one other person.

The sudden shift prompted a backlash from GPs, who said it had left them ill prepared for dealing with queries from anxious patients. Just two days earlier, NHS England had published revised advice for GPs stating that shielded patients should continue to stay at home, adding to the sense of confusion. ${ }^{2}$

The announcement appeared to surprise even NHS England's national medical director of primary care Nikita Kanani, who tweeted on 31 May, "I have-understandably-had a number of messages about the shielding announcements made last night and expected today. As soon as I know more, I will post on this thread. In the meantime, please continue to follow the guidance set out." ${ }^{3}$ The Health Service Journal later reported that NHS England "knew nothing" of the change before it was announced. ${ }^{4}$ Prakash Kachhala, a GP in Nottinghamshire, told The BMJ that he only learnt of the change to the advice on the news. "We've had a number of worried patients contact us wanting to speak to a GP today (1 June) and I suspect we'll have a steady stream all week," he said.

Joe McManners, a GP in Oxford, called the announcement "disorganised." He told The BMJ, "With some more planning and warning GPs could have put information on surgery websites, texted advice, or at least been prepared for lots of queries. Even now there seems scant information available to inform choices.

"The risk may well change quickly and within the shielding group there's a wide range of vulnerabilities."

Alex Gates, a GP in Bath, said the government had "completely lost my trust." Writing on Twitter, he urged colleagues, "Don't do what feels unsafe just because the government tell you it is safe to do so. I no longer feel happy telling patients to follow guidelines."

Martin Marshall, chair of the Royal College of GPs, said, "We would advise extreme caution, particularly for those who are in the most high risk groups, such as patients with cancer or serious long term conditions including respiratory and heart disease.

"The latest government advice is just that-it's not a 'green light' to return to our previous way of life. There is a very real risk that all the good work we have achieved so far could be swiftly undone, with serious consequences."

Richard Vautrey, chair of the BMA's GP committee, said that even on Monday morning when the changes were in place, practices had not had any further guidance. "It's imperative that practices are informed before public announcements, on any subject matter, so that they are in a position to support their patients as effectively as possible," he said.

Stephen Griffin, associate professor in the School of Medicine, University of Leeds, questioned the evidence behind the decision, which he said "seems to lack any obvious rationale other than to add to an ongoing 'good news' narrative that appears to have little grounding in reality."

Griffin said, "As we've heard from the deputy chief medical officer Jonathan Van Tam, members of SAGE and its unofficial counterpart, and numerous other members of the scientific community, the daily case incidence, death rate, and R0 in the UK does not represent a controlled, safe scenario."

A Department of Health and Social Care spokesperson said, "We have engaged extensively with partners and the healthcare system throughout this process and will continue to, particularly in the next two weeks when more substantive measures are considered. The announcement on 31 May signalled this period of engagement.

"We want to make life easier for the most vulnerable and, as the number of covid-19 cases continues to fall, the evidence shows those shielding can choose to spend time safely outside if they wish, as long as they follow social distancing guidelines."

1 Guidance on shielding and protecting people who are clinically extremely vulnerable from covid-19. 31 May 2020. www.gov.uk/government/publications/guidance-on-shielding-andprotecting-extremely-vulnerable-persons-from-covid-19/guidance-on-shielding-andprotecting-extremely-vulnerable-persons-from-covid-19.

2 NHS England. Guidance and standard operating procedures: general practice in the context of coronavirus (covid-19). 29 May 2020. www.england.nhs.uk/coronavirus/wpcontent/uploads/sites/52/2020/03/CO485-COVID-19-Primary-Care-SOP-GP-Practice-V329-May-2020.pdf.

3 Dr Nikita Kanani. 31 May 2020. https://twitter.com/NikkiKF/status/1267089120263798784? $\mathrm{s}=20$.

4 Brennan S. NHS England 'knew nothing' of change to shielding guidance. HSJ. 1 June 2020. www.hsj.co.uk/policy-and-regulation/nhs-england-knew-nothing-of-change-toshielding-guidance/7027747.article

5 Dr Alex Gates. 1 June 2020. https://twitter.com/dr_alex_gates/status/ 1267344721480990720 
This article is made freely available for use in accordance with BMJ's website terms and conditions for the duration of the covid-19 pandemic or until otherwise determined by BMJ. You may use, download and print the article for any lawful, non-commercial purpose (including text and data mining) provided that all copyright notices and trade marks are retained.

https://bmj.com/coronavirus/usage 